\title{
Activation of the ER stress and calcium signaling in angiomyolipoma
}

\author{
B. NOVOTNA ${ }^{1}$, M. TAKACOVA ${ }^{2}$, S. HUDECOVA ${ }^{3}$, L. LENCESOVA ${ }^{3}$, J. BREZA JR. ${ }^{4}$, A. MISAK ${ }^{3}$, L. CSADEROVA², S. PASTOREKOVA², O. KRIZANOVA ${ }^{3, *}$, \\ J. BREZA ${ }^{4}$
}

${ }^{1}$ Department of Neuropediatrics, University Hospital Carl Gustav Carus, Dresden, Germany; ${ }^{2}$ Institute of Virology, Biomedical Research Center, Slovak Academy of Sciences, Bratislava, Slovakia; ${ }^{3}$ Institute for Clinical and Translational Research, Biomedical Research Center, Slovak Academy of Sciences, Bratislava, Slovakia; ${ }^{4}$ Department of Urology, University Hospital, Bratislava, Slovakia

*Correspondence: olga.krizanova@savba.sk

Received February 23, 2016 / Accepted April 25, 2016

\begin{abstract}
Renal angiomyolipomas (AMLs) are uncommon benign tumors that occur sporadically or as a part of tuberous sclerosis complex (TSC). Risk of life threatening hemorrhage is the main clinical concern. Although several evidences suggest that hyper-activation of the mammalian target of rapamycin complex 1 (mTORC1) signaling pathway is crucial for these tumors, modulation of other metabolic pathways might affect tumor growth and progression. Therefore, we aimed to further characterize angiomyolipoma by TSC1/TSC2 expression, hypoxic status, expression of endoplasmic reticulum (ER) stress markers and calcium transport from the ER through the inositol 1,4,5-trisphosphate $\left(\mathrm{IP}_{3}\right)$ receptors. Despite our expectations, angiomyolipoma were not hypoxic, as determined by absent expression of the carbonic anhydrase IX, which is a reliable marker of hypoxia. This was in accord with very low expression of TSC1 (that is associated with HIF activation) and a high expression of TSC2. Angiomyolipoma specimens also showed a significant upregulation of an anti-apoptotic marker Bcl2 when compared to healthy kidney tissue supporting the induction of pro-survival signaling. Moreover, angiomyolipoma specimens showed the overexpression of the ER stress markers XBP1, CHOP and ATF4 as well as of the mediators of calcium metabolism, namely the type 1 and 2, but not the type $3 \mathrm{IP}_{3}$ receptors. These data suggest that the ER stress response, survival and calcium metabolism-related pathways but not hypoxia is an important component of the angiomyolipoma pathogenesis.
\end{abstract}

Key words: angiomyolipoma, endoplasmic reticulum stress, inositol 1,4,5-trisphosphate receptors

Renal angiomyolipomas (AMLs) are benign tumors composed of vascular, fat and smooth muscle elements. They occur sporadically $(80 \%)$ and are typical for adults, with a strong female predilection ( $\mathrm{F}: \mathrm{M}=4: 1)[1]$, or in $20 \%$ as a part of tuberous sclerosis complex (TSC). TSC is a rare genetic disorder, in which patients develop benign tumors in several organ systems. In these cases AMLs occur earlier (usually identified before the age of 10 years), they are larger and far more numerous.

Renal AMLs can be seen in $80 \%$ of patients with TSC. They are the most common cause of mortality in these patients [2]. AMLs grow slowly, with an increasing acceleration in boys before puberty and in girls after menarche. In patients with TSC, they become typically symptomatic in the second or third decade of life. Dangerous/life threatening is a possible retroperitoneal rupture of AML, which can be fatal. The risk of bleeding is proportional to the size of the lesion $(>4 \mathrm{~cm}$ diameter). Shock due to a severe hemorrhage from the rup- tured AML is described as Wunderlich syndrome [3]. Patients suffering from AMLs may have numerous other symptoms and signs, such as flank pain, hematuria, renal hypertension or also renal failure. Small asymptomatic AMLs do not need treatment. All AMLs above $4 \mathrm{~cm}$ in diameter are indication for a scheduled treatment to predict a possible rupture either by embolization of the renal artery or by nephron sparing surgery [4]. Possible malignant transformation of AMLs occurs with a prevalence of $2.5-4.0 \%$ [5], which is major problem causing patient's morbidity.

Angiomyolipomas are caused by mutations in either the TSC1 or TSC2 genes, which govern cell growth and proliferation. TSC gene products, TSC1 (hamartin) and TSC2 (tuberin), form a complex critical to the integration of cellular sensory input, such as growth factors, genomic integrity, cellular energy supply, and growth substrate availability [6]. The results of these inputs include growth and proliferation, or cell cycle arrest and senescence, autophagy, and cell death. Be- 
cause mammalian target of rapamycin complex 1 (mTORC1) is downstream of the hamartin/tuberin complex, a clinical trial was undertaken to determine whether modulating this component would affect the angiomyolipoma. The results of this clinical proof-of principle trial suggest that rapamycin and analogues may be beneficial in controlling TSC angiomyolipoma growth [7]. Since 2010 multiple clinical studies have shown a new therapeutic option, drug therapy with mammalian target of rapamycin (mTOR) inhibitor. The indication for this therapy is detection of multiple bilateral AMLs. Treatment has not only a therapeutic, but also prophylactic effect [8]. By modulating the mTOR pathway, cells can survive and recover, or the processes can push the cells past a point of no return, resulting in a cell death. Whereas mammalian target of rapamycin (mTOR) inhibition leads to autophagy, mTOR overactivity, such as that occurring in TSC, leads to endoplasmic reticulum (ER) stress [6]. Kang et al. [9] found that cells with mutation in either TSC1 or TSC2 are hypersensitive to ER stress and undergo apoptosis. These results are in agreement with the work of Siroky et al. [10], who suggested that human angiomyolipoma cells are uniquely susceptible to agents that exacerbate ER stress.

ER-stress is engaged in many cellular functions, such as protein synthesis, folding and storage, as well as in calcium signaling [11]. When disturbances in these functions occur and level of misfolded proteins in the ER increase, goal of ER stress is to enhance protein folding, reduce new protein synthesis and clear misfolded proteins. When the above-mentioned functions are rapidly decreased, ER stress can trigger apoptotic cell death for elimination defective cells [12].

Modified calcium signaling is an important feature of the ER-stress. ER stress is characterized by ER calcium depletion [13], which is caused either by up-regulated expression and/or function of IP $\mathrm{IP}_{3}$ receptors or ryanodine receptors, or impaired expression and/or function of the sarco/endoplasmic ATPase. ER stress is linked to a calcium-dependent mitochondrial apoptosis [14], preferentially through the type 1 inositol 1,4,5trisphosphate receptors (IP Rs) $[13 ; 15]$. Therefore, we propose that in angiomyolipoma, IP ${ }_{3}$ Rs might be modulated due to the ER-stress and they might participate on apoptosis induction also in angiomyolipoma.

Based on the current knowledge on angiomyolipoma we aimed to further characterize these tumors by determining TSC1/TSC2 expression, hypoxic status, occurrence of the ER stress and apoptosis. Further, we intended to elucidate what types of IP ${ }_{3}$ Rs are involved in development of ER stress in angiomyolipoma.

\section{Patients and methods}

Patient information and tumor samples. Although these tumors are quite uncommon, we got samples from kidney angiomyolipoma of 6 patients ( 6 samples from unaffected kidney and 8 samples from angiomyolipoma) after the surgery. The ethics committee of the Medical Faculty approved the present study and verbal consent was obtained from these participants prior to surgery. All samples were tested on changes in the gene expression profile of ER stress markers. Part of the unaffected kidney from the same patient was taken as a corresponding healthy control. All samples were stored in RNA later.

Immunofluorescence. Dissected tissues were embedded in paraffin according to the standard histological procedure. Sections $(4 \mu \mathrm{m})$ were placed on polylysine-coated slides, dewaxed and rehydrated. Non-specific binding was blocked by incubation with PBS containing 3\% bovine serum albumin (BSA) for $60 \mathrm{~min}$ at $37^{\circ} \mathrm{C}$. The sections were then incubated with primary antibody diluted 1:100 in PBS with $1 \%$ BSA (PBS-BSA) for $1 \mathrm{~h}$ at $37^{\circ} \mathrm{C}$. Polyclonal rabbit TSC2 antibody (Antibodies online) and TSC1 (Antibodies online) were used. TSC1 antibody was raised against a 15 amino acid peptide from the middle region of human TSC1. TSC2 antibody was produced against synthesized peptide derived from human Tuberin/TSC2. Afterwards, the cells were washed three times with $\mathrm{PBS}$ for $5 \mathrm{~min}$, incubated with secondary antibody diluted 1:1000 in PBS/BSA for $1 \mathrm{~h}$ at $37^{\circ} \mathrm{C}$, and washed as described previously. Finally, the sections were mounted onto slides in mounting medium with Citifluor (Agar Scientific Ltd., Essex, UK) and analyzed by laser scanning confocal microscopy (LSM 510 MetaMicroscope, Zeiss). Images were taken with a Plan Apochromat 20x/0.8 objective. Images of all samples were acquired with the same microscope setup.

Immunohistochemistry. Dissected tissues were embedded in paraffin according to the standard histological procedure. Sections $(4 \mu \mathrm{m})$ were placed on polylysine-coated slides, dewaxed and rehydrated. For TSC2, polyclonal rabbit TSC2 antibody (Antibodies online) was used. This antibody was raised against synthesized peptide derived from human Tuberin. For ATF4 and XBP1 detection, antigen retrieval was carried out with citrate buffer, $\mathrm{pH} 6$, for $5 \mathrm{~min}$ at $125^{\circ} \mathrm{C}$ using Pascal pressure chamber (Dako) and immunostaining procedure was performed using the DakoCytomation EnVision $^{\circ}+$ System-HRP (DAB) for use with either rabbit (ATF4) or mouse (XBP1) primary antibodies according to the manufacturer's instructions: a) peroxidase and protein block (10 min each); b) incubation with primary antibody overnight at $4^{\circ} \mathrm{C}$ (both antibodies diluted 1:100 in antibody diluent) or PBS (negative control); c) incubation for $30 \mathrm{~min}$ with secondary antibody. Staining was visualized with $\mathrm{DAB}$ solution for $1 \mathrm{~min}$ with 3,3-diaminobenzidine as a chromogenic substrate. Immunostaining of carbonic anhydrase IX (CA IX) was performed as described elsewhere [16]. The slides were washed in PBS with $0.1 \%$ Tween-20 for 10 min after step a, twice for 10 min after steps b and c, and three times in distilled water after visualization with DAB. All incubations and washings were carried out at room temperature. Finally, the sections were counterstained with Mayer's hematoxylin, washed for $5 \mathrm{~min}$ and were mounted in Aquamont (Merck, Darmstadt, Germany). The stained sections were examined with Leica DM4500 B microscope and photographed with Leica DFC480 camera. 
Western blot analysis. Western blot analysis was performed as described in our previous work [13]. Following primary antibodies were used in this assay: rabbit polyclonal antibody to Caspase 3 (Calbiochem, Darmstadt, Germany), rabbit polyclonal antibody to CREB-2 (also designated ATF 4; Santa Cruz Biotechnology, Inc., USA), rabbit polyclonal antibody to GADD 153 (CHOP; Santa Cruz Biotechnology, Inc., USA).

Analysis of the gene expression by real-time PCR. For the RNA isolation, tissue samples were collected to the RNA later solution (Sigma Aldrich,USA). Population of total RNAs was isolated by TRI Reagent (MRC Ltd., Cincinnati, OH, USA). Briefly, tissue samples (app.1mg) were homogenized in TRI Reagent solution. After 5 minutes at room temperature, the homogenate was extracted by chloroform. This mixture was centrifuged $15 \mathrm{~min}$. at $10000 \mathrm{xg}$ at $4^{\circ} \mathrm{C}$. RNAs in the aqueous phase were precipitated by isopropanol. RNA pellet was washed with $75 \%$ ethanol and stored in $96 \%$ ethanol at $-70^{\circ} \mathrm{C}$. The purity and integrity of isolated RNAs was checked on GeneQuant Pro spectrophotometer (Amersham Biosciences, Buckinghamshire, United Kingdom). Reverse transcription was performed using $1.5 \mu \mathrm{g}$ of total RNAs and Ready-To-Go You-Prime First-Strand Beads (GE Healthcare-Life Sciences, USA) with $\mathrm{pd}(\mathrm{N} 6)$ primer. The real-time PCR amplification and detection was carried out on the PikoReal 96 qPCR system (Thermo Fisher Scientific, Hampshire, UK). SYBR Green Master Mix with ROX reference dye (Thermo Fisher Scientific, Hampshire, UK), primers at $5 \mathrm{pmol}$ and $10 \%$ of the reverse transcription product were mixed to a final volume of $20 \mu \mathrm{l}$. Master Mix with primers and template was separately loaded onto 96-well plates (Thermo Fisher Scientific, Hampshire,
UK). Plates were centrifuged to remove any air bubbles in the wells. Each sample was run in duplicates and with 1 'no template' control. Each cycle consisted of $15 \mathrm{~s}$ at $95^{\circ} \mathrm{C}$, $30 \mathrm{~s}$ at $60^{\circ} \mathrm{C}$ and $30 \mathrm{~s}$ at $72^{\circ} \mathrm{C}$ for $40 \mathrm{cycles}$ and a denaturing step for $7 \mathrm{~min}$ at $95^{\circ} \mathrm{C}$. Primers used for specific genes were the same as for the conventional PCR (Table 1). To exclude the presence of non-specific products, a routine melting curve analysis was performed after finishing the amplification. This was done by high resolution data collection during an incremental temperature increase from 60 to $95^{\circ} \mathrm{C}$. Data were analyzed with PIKOREAL software version 2.1 (Thermo Fisher Scientific) and inspected to determine artifacts (loading errors, threshold errors). Baseline levels for each gene were computed automatically. Results were analyzed as a peak area for every well and quantified relatively from Cq values according to the formula $\Delta \Delta \mathrm{Cq}=\Delta \mathrm{cq}$ sample $-\Delta \mathrm{Cq}$ housekeeper, where the human cyclophiline was used as housekeeper.

Statistical analysis. Each control represents an average of 6 healthy parts of kidney and AML represents the average of 8 samples from 6 patients. Results are presented as mean \pm S.E.M. Statistical differences between the groups were determined by T-test. Statistical significance of at least $\mathrm{p}<0.05$ was considered to be significant. Analyses were performed using Instat (GraphPad Software, Inc., San Diego, CA, USA).

\section{Results}

Immunoflurescent analysis of 8 angiomylipoma specimens from 6 patients displayed the TSC2 protein signal, but very weak TSC1 staining signal (Figure 1A). Hypoxic status was

Table 1. Primers used for the real-time PCR quantification.

\begin{tabular}{|c|c|c|c|}
\hline Primer & Seqence $5^{\prime} \rightarrow 3^{\prime}$ & Position & GI \\
\hline $\mathrm{IP}_{3} \mathrm{R} 1$ forward & GGT TTC ATT TGC AAG TTA ATA AAG & $5162-5184$ & 10835022 \\
\hline $\mathrm{IP}_{3} \mathrm{R} 1$ reverse & AAT GCT TTC ATG GAA CAC TCG GTC & $5543-5566$ & \\
\hline $\mathrm{IP}_{3} \mathrm{R} 2$ forward & ATG CGT GTG TCC TTG GAT GC & $439-458$ & 4504792 \\
\hline $\mathrm{IP}_{3} \mathrm{R} 2$ reverse & GTA GCA GAA GTA GCT GAT TG & $808-827$ & \\
\hline $\mathrm{IP}_{3} \mathrm{R} 3$ forward & CTG CGA CTG GGA AGA ACA CTG & $8306-8327$ & 305632833 \\
\hline $\mathrm{IP}_{3} \mathrm{R} 3$ reverse & TCC TGA CAG TCG AGA CTC CGA & $8408-8429$ & \\
\hline CA IX forward & TAT CTG CAG TCC TGC CCT CTG & $980-1000$ & 169636419 \\
\hline CA IX reverse & CAG AGG GTG TCA GAG AGG GTG T & $1112-1133$ & \\
\hline XBP1 forward & TGG CAT CCT GGC TTG CCT CCA & $1516-1536$ & 18148381 \\
\hline $\mathrm{XBP} 1$ reverse & TCG AGG CCA CGA AGG CCT TTT A & $1739-1760$ & \\
\hline ATF4 forward & GTG GCC AAG CAC TTC AAA CC & $245-262$ & 109451023 \\
\hline ATF4 reverse & CCC GGA GAA GGC ATC CTC & $137-154$ & \\
\hline Bax forward & AGA GGA TGA TTG CCG CCG & 299-316 & 163659848 \\
\hline Bax reverse & CAA CCA CCC TGG TCT TGC ATC & $542-522$ & \\
\hline $\mathrm{Bcl} 2$ forward & TCC ATG TCT TTG GAC AAC CA & $5689-5708$ & 72198188 \\
\hline $\mathrm{Bcl} 2$ reverse & CTC CAC CAG TGT TCC CAT CT & $5891-5872$ & \\
\hline CHOP forward & GGA GCT GGA AGC CTG GTA TGA GG & $214-236$ & 304282233 \\
\hline CHOP reverse & TCC CTG GTC AGG CGC TCG ATT TCC & $596-618$ & \\
\hline
\end{tabular}


verified by the PCR amplification and immunohistochemical staining of the CA IX, which is a strong marker of hypoxia. We observed a very weak signal of the CA9 mRNA in both control and angiomyolipoma's samples (Figure 1B) and no signal in the CA IX protein in angiomyolipoma tissue sections of three patients (Figure 1C), which clearly showed that angiomyolipoma were not hypoxic. Using real-time PCR we observed increased gene expression of markers of the ER stress - XBP1 (Figure 2A), CHOP (Figure 2B) and ATF4 (Figure 2C), compared to healthy kidney tissue from the same patient. Immunohistochemical staining with appropriate antibodies also showed the elevated XBP1 and ATF4 proteins (Figure 2D, upper part), and thus the occurrence of the ER stress. Also, Western blot analysis revealed increased CHOP and ATF4 levels in AML compared to healthy kidney tissue (Figure 2D, lower part).

Thus, ER stress was not induced by hypoxia. Since ER stress is characterized by a depletion of calcium, we tested the involvement of individual types of $\mathrm{IP}_{3}$ receptors in angiomyolipoma samples. We have found that the gene expression of the type 1 (Figure $3 \mathrm{~A}$ ) and type 2 (Figure 3B) $\mathrm{IP}_{3}$ Rs was significantly increased compared to healthy renal tissue from the same patients, while gene expression of the type $3 \mathrm{IP}_{3}$ Rs was not changed (Figure 3C). In order to estimate the process of apoptosis, we determined the $\mathrm{Bax}$ and $\mathrm{Bcl} 2$ gene expression (Figure 4A). While the
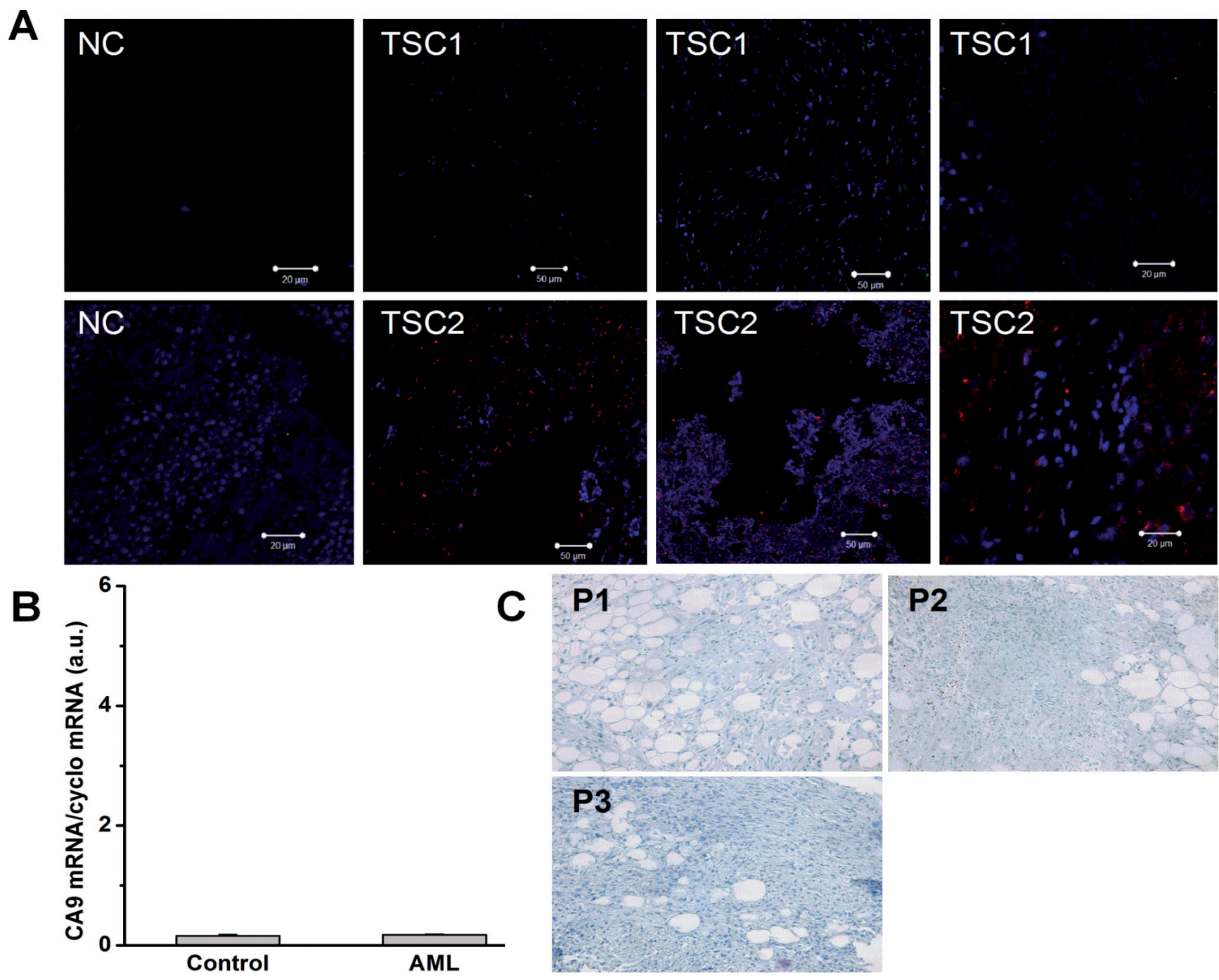

Figure 1. Immunofluorescent staining of the slices from angiomyolipoma samples from three patients with TSC1 and/or TSC2 antibodies (A). Nuclei were stained with DAPI. For images and corresponding negative controls, bar was 20 or $50 \mu \mathrm{m}$. To check, whether angiomyolipoma were hypoxic, we determined relative changes in the gene expression of carbonic anhydrase IX (B; CA9) in healthy kidney (Control, n=6) and angiomyolipoma (AML, $\mathrm{n}=8$ ). Values of the CA9 mRNA were not different from those from healthy tissue (B). Results are displayed as mean \pm SEM. No specific signal was observed by immunohistochemistry using anti-CA IX mouse monoclonal antibody (C). Original magnification x 200. 
expression of Bax does not differ in healthy renal sample and angiomyolipoma, $\mathrm{Bcl} 2$ was significantly increased in angiomyolipoma. Thus, $\mathrm{Bax} / \mathrm{Bcl} 2$ ratio was significantly lower in angiomyolipoma compared to healthy samples (Figure 4A), suggesting suppressed apoptosis. Results were verified by Western blot analysis with caspase 3 antibody, detecting both, latent and active form (Figure 4B). Expression of the latent form was high in healthy control tissue, but in AML it was very low. Active form is almost unvisible in control (by Annexin V-FLUOS assay only approximately $5 \%$ of cells are apoptotic; not shown), and is not detectable in AML (Figure 4B).

\section{Discussion}

Renal AMLs are the most common benign tumors of the kidney and are derived from perivascular epithelial cells. Although the origin of these lesions is contested, the most
XBP1
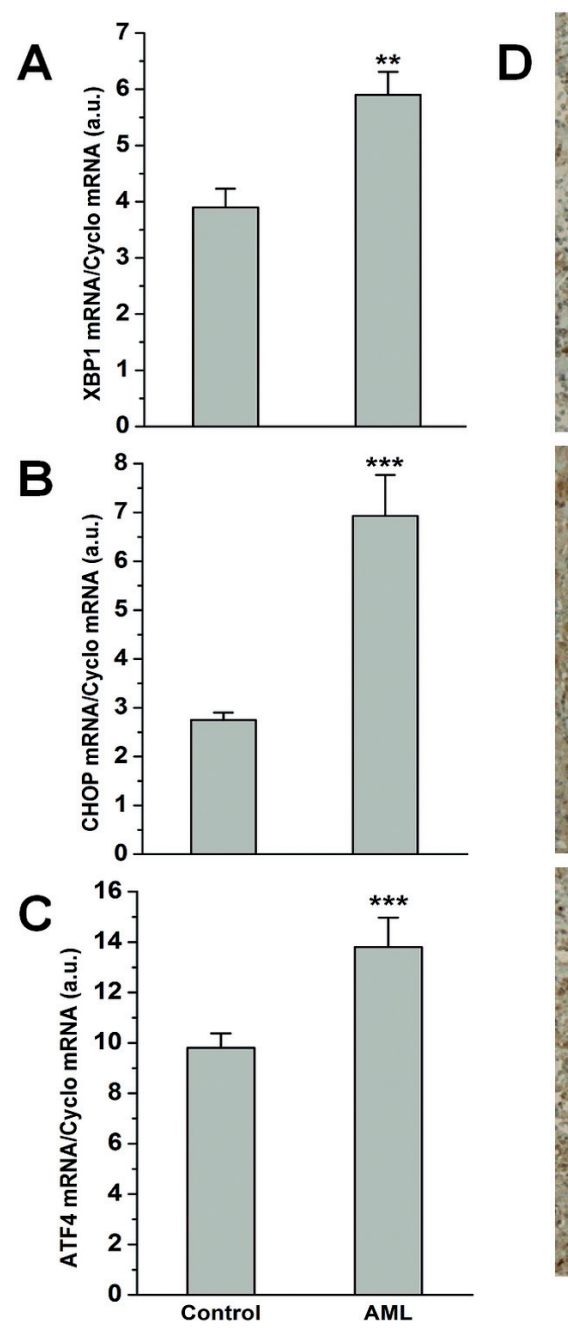
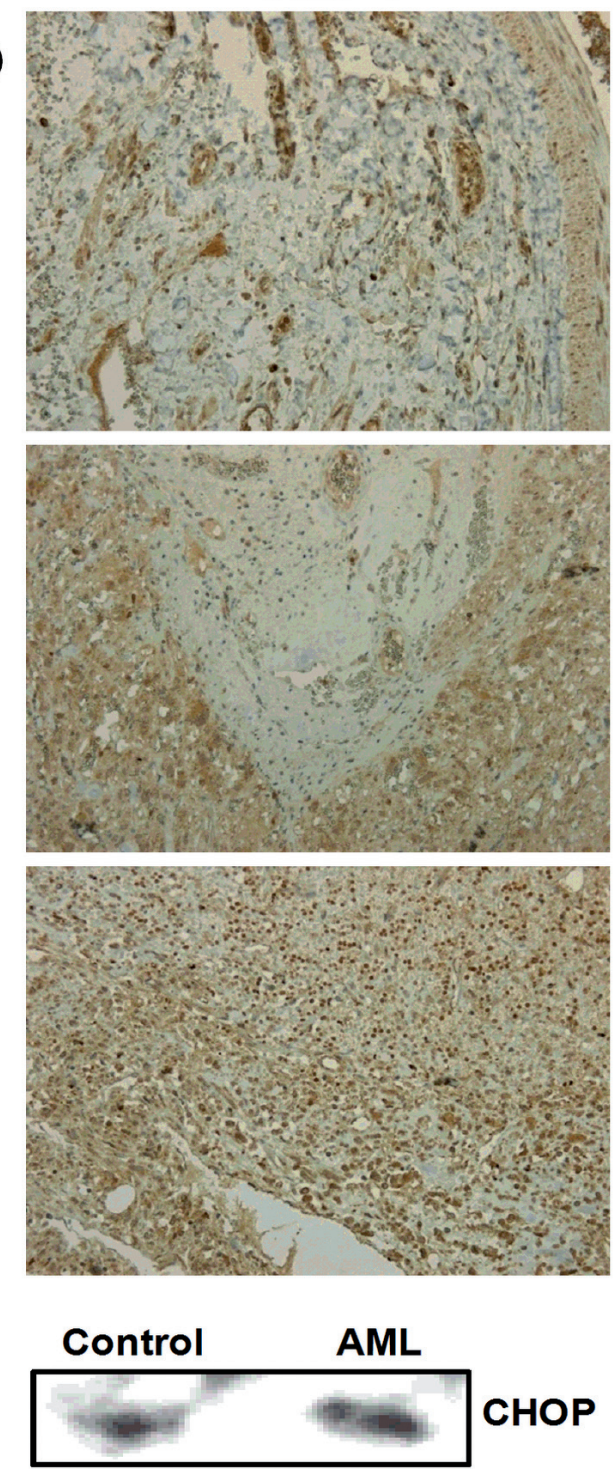

ATF4
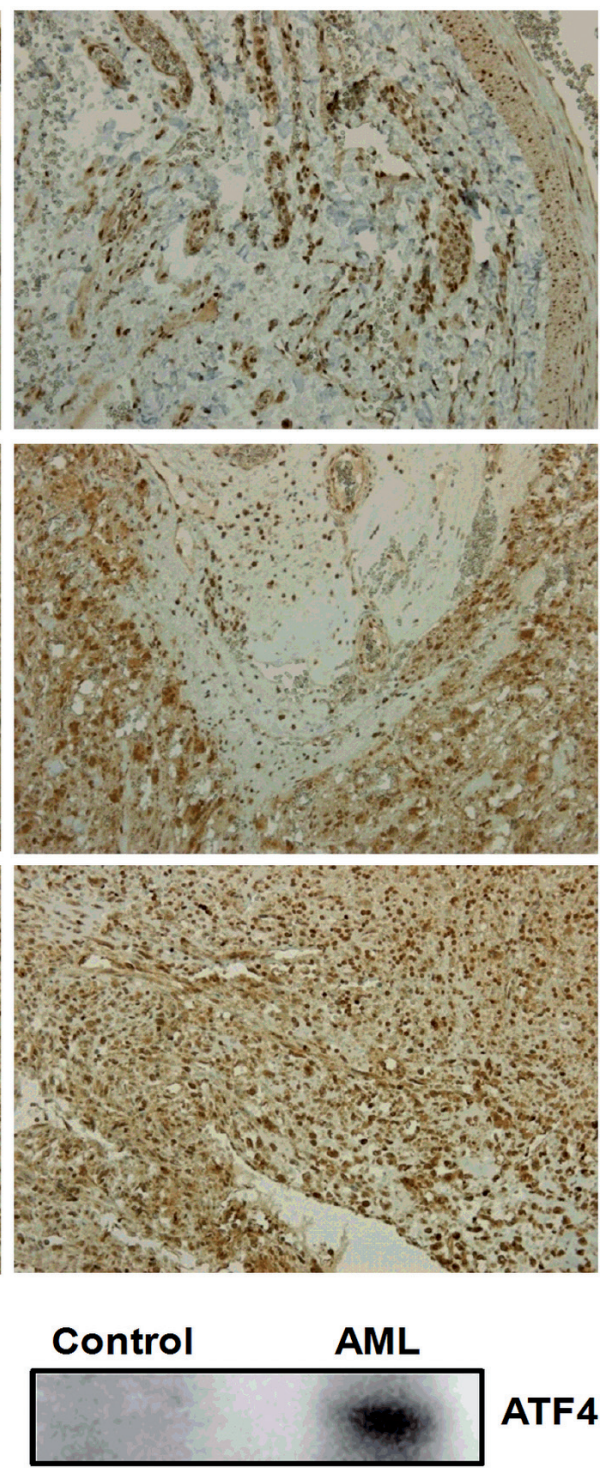

Figure 2. Relative changes in the gene expression of X-box binding protein 1 (A; XBP1), CHOP (B) and activating transcription factor 4 (C; ATF4) in healthy kidney (Control, $n=6$ ) and angiomyolipoma (AML, $n=8$ ). Values of XBP1, CHOP and ATF4 mRNA were significantly higher in all angiomyolipoma samples compared to those from healthy tissue. Results on the gene expression are displayed as mean \pm SEM. Statistical significance ${ }^{\star *}-\mathbf{p}<0.001$ and $^{* * *}-\mathbf{p}<0.0001$. Immunohistochemical staining of XBP1 and ATF4 in tumor tissue samples (D, upper part). Positive signal (brown color) is clearly visible in serial tissue sections from three angiomyolipomas. Original magnification $\mathrm{x} 200$. Also, Western blots of CHOP and ATF4 proves increased levels of these markers in angiomyolipoma, compared to healthy tissue (D, lower part). 

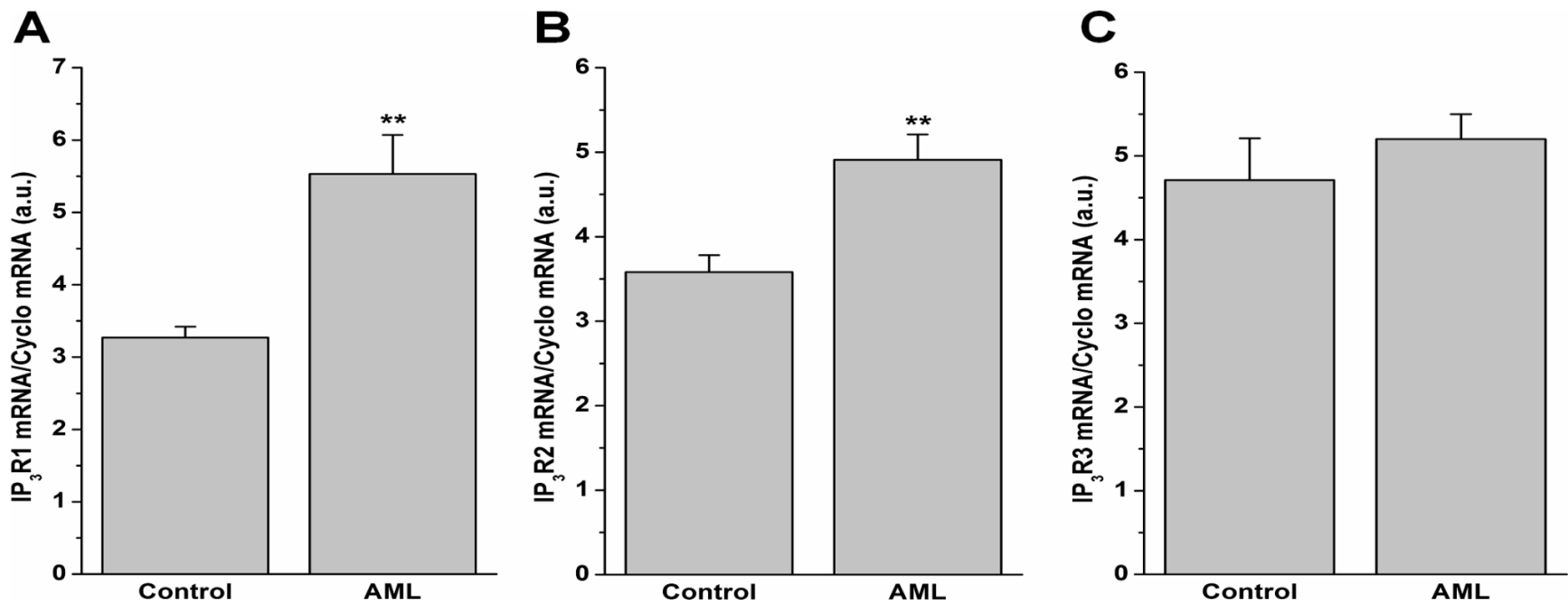

Figure 3. Results of the gene expression of the $\mathrm{IP}_{3} \mathrm{R} 1(\mathrm{~A}), \mathrm{IP}_{3} \mathrm{R} 2(\mathrm{~B})$ and $\mathrm{IP}_{3} \mathrm{R} 3(\mathrm{C})$, as determined relatively to the housekeeper Cyclophilin $\mathrm{A}$. Results are from real-time PCR. We observed higher expression of genes coding IP ${ }_{3} R_{1}$ andIP ${ }_{3} R 2$ in angiomyolipoma compared to a healthy renal tissue. No changes in the expression of gene coding $\mathrm{IP}_{3} \mathrm{R} 3$ was observed. Results are displayed as mean \pm SEM. Statistical significance ${ }^{\star *}-\mathbf{p}<0.001$.

widely accepted theory suggests that these benign tumors originate from metaplastic change of the reticuloendothelial cells of capillaries in response to stimuli [17]. Risk of life threatening hemorrhage is the main clinical concern.
Although associated with TSC, these tumors occur sporadically. Central to TSC pathology is hyper-activation of the mammalian target of rapamycin complex 1 (mTORC1) signaling pathway, which is a key controller of cell growth.
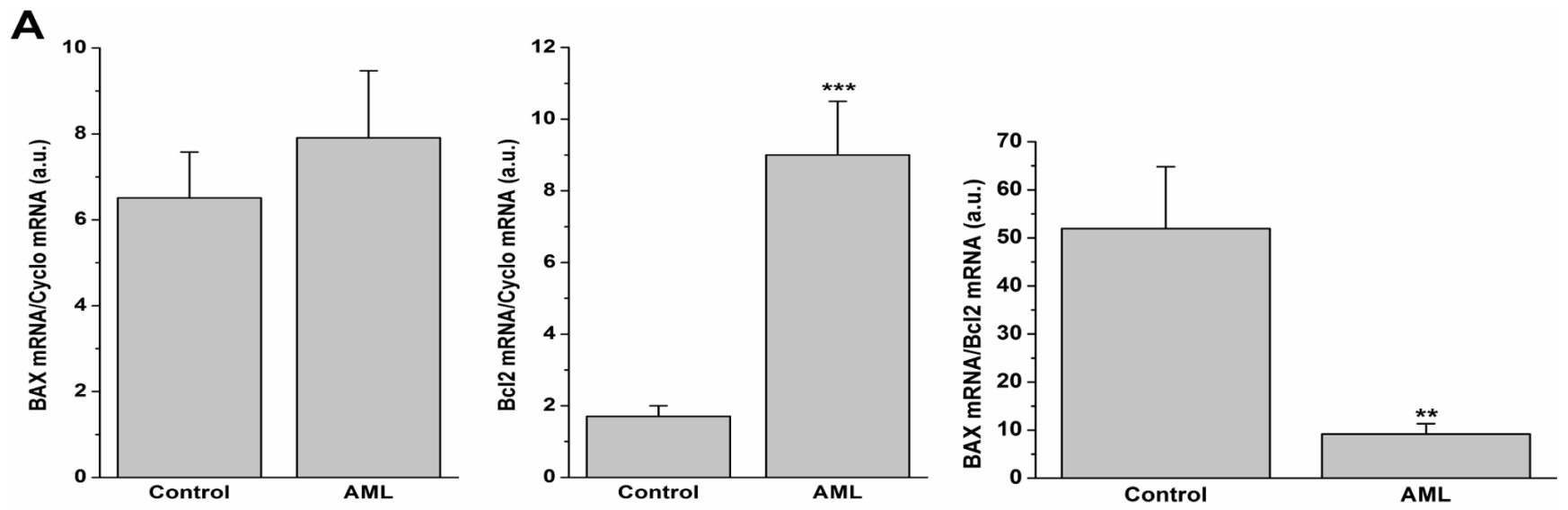

$\mathbf{B}$

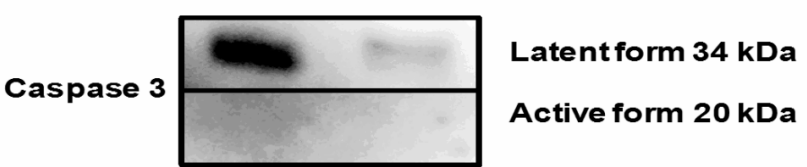

Figure 4. Relative changes in the gene expression of $\mathrm{BAX}, \mathrm{Bcl} 2$ and $\mathrm{BAX} / \mathrm{Bcl} 2$ ratio in healthy kidney (Control, $\mathrm{n}=6$ ) and angiomyolipoma (AML, $\mathrm{n}=8$ ). Bax mRNA was the same in control samples and in AML, while the Bcl2 mRNA was significantly higher in all AML compared to samples from healthy tissue. $\mathrm{BAX} / \mathrm{Bcl} 2$ ratio was significantly decreased in AML compared to samples from healthy kidney (A). Western blot analysis with caspase 3 antibody shows much higher expression of the latent caspase 3 in control tissue compared to AML, and no signal of active caspase 3 (B). Results are displayed as mean \pm SEM. Statistical significance ${ }^{\star * *}-\mathbf{p}<0.0001$. 
By modulation of the mTOR pathway, cells can survive and recover, or the processes can push the cells past a point of no return, resulting in the cell death. Whereas mammalian target of rapamycin (mTOR) inhibition leads to autophagy, mTOR overactivity, such as that occurring in TSC, leads to ER stress [6]. Development of the ER stress in angiomyolipoma was described in the few papers $[9,10]$. We also have shown that angiomyolipoma specimens exhibit significantly increased expression of markers of the ER stress - ATF4, $\mathrm{CHOP}$ and XBP1. All these results are in agreement with meta-analytic data from GENEVESTIGATOR [18], where ER stress markers, especially ATF4 were highly expressed in angiomyolipoma (Figure 5). Therefore, understanding mechanisms of the ER stress development and functional consequences might be useful to develop strategies to evolve potential drug therapy. Cell-death and survival decisions are critically controlled by intracellular $\mathrm{Ca}^{2+}$ homeostasis and dynamics at the level of the ER. IP ${ }_{3}$ Rs play a pivotal role in these processes by mediating $\mathrm{Ca}^{2+}$ flux from the ER into the cytosol and mitochondria. Hence, it is clear that many pro-survival and pro-death signaling pathways and proteins affect $\mathrm{Ca}^{2+}$ signaling by directly targeting $\mathrm{IP}_{3} \mathrm{R}$ channels, which can happen in an IP R-isoform-dependent manner $[19,20]$. ER stress is characterized by calcium depletion, preferentially through the IP ${ }_{3}$ Rs. Therefore, gene expression of the individual types of IP Rs was determined in angiomyolipoma samples and corresponding controls. We observed increased expression of the type 1 and 2, but not the type 3 mRNA of IP ${ }_{3}$ Rs. We proposed that these receptors might be involved in the ER stress development in angiomyolipoma. High expression of the $\mathrm{IP}_{3} \mathrm{R} 1$ in angiomyolipoma is shown by meta-analysis (Figure 5), thus proving our results. $\mathrm{IP}_{3} \mathrm{Rs}$ of type 1 and 2 are known to participate in activation of the mitochondrial pathway of apoptosis [for review see 19]. Results from the meta-analysis (Figure 5) support the idea about activated mitochondrial apoptotic pathway in angiomyolipoma, since expression of the Cytochrome C (CyCS) was high. Apoptosis was evaluated by $\mathrm{Bax}$ and $\mathrm{Bcl} 2$ expression. While Bax expression was the same in the samples of healthy kidney controls, Bcl2 expression was significantly higher in angiomyolipoma compared to healthy controls. The $\mathrm{Bcl} 2$ protein was shown to contribute to the pathophysiology of cancer and the resistance of cancer to therapeutic agents by its ability to inhibit apoptosis $[21,22]$. Thus, our results suggest that the process of apoptosis is inhibited in angiomyolipoma samples. Inhibited apoptosis in angiomyolipoma was observed also by Carelli and co-workers [23], who clearly showed that angiomyolipoma-derived human smooth muscle TSC2-/- cells express the apoptosis inhibitor protein survivin when exposed to IGF-1. Survivin originally was isolated as a member of IAP family, and it was suggested that it plays a fundamental role in inhibiting apoptosis and regulating the mitotic process and cell proliferation [24]. Survivin affects the initiation of mitochondrial-mediated apoptosis by binding the Smac/DIABLO released from mitochondria membranes,

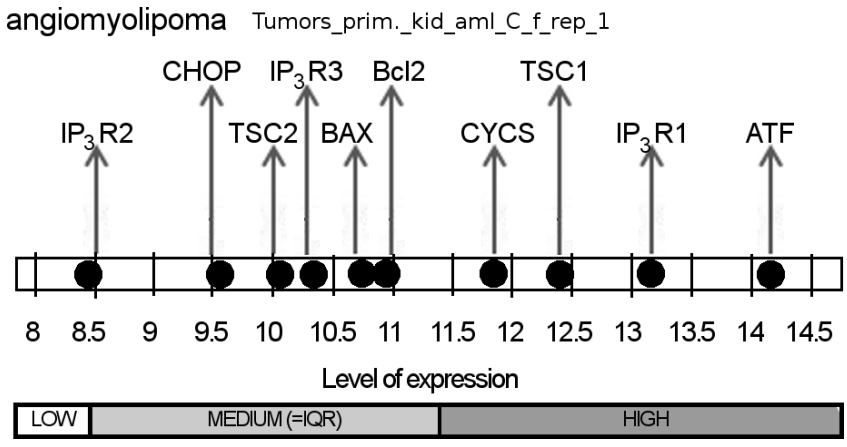

Figure 5. Results of the gene expression of $I P_{3} R s\left(I_{3} R 1, I_{3} R 2, I_{3} R 3\right)$, ER stress markers (ATF4, CHOP), BAX, Bcl2 and cytochrome C (CYCS) displayed from GENEVESTIGATOR - a reference expression database for the meta-analysis of transcriptomes [27]. In angiomyolipoma, according to this database, high expression was observed in CYCS, TSC1, $\mathrm{IP}_{3} \mathrm{R} 1$ and ATF4.

and then inhibiting caspase-9 activation [25]. Nevertheless, Kang et al. [9] found that cells with mutation in either TSC1 or TSC2 are hypersensitive to endoplasmic reticulum (ER) stress and undergo apoptosis. In our samples, we found noticeably shifted expression of Bcl2/Bax family proteins in favor of anti-apoptotic $\mathrm{Bcl} 2$. Besides of the anti-apoptotic role, it has been documented by several groups that $\mathrm{Bcl}-2$ family of proteins constitutes a rheostat for the fine tuning of calcium metabolism and that Bcl-2 and Bcl-XL form a protein complex with the $\mathrm{IP}_{3} \mathrm{R}$ modulating its activity $[26,27]$. Therefore, we can speculate that elevated number of $\mathrm{IP}_{3} \mathrm{R} 1$ and 2 in our angiomyolipoma samples can interact with Bcl2. Nevertheless, issue of the apoptosis in angiomyolipoma is still open. Similarly, in 2002 it was noticed that TSC-associated renal angiomyolipomas consist of abnormal blood vessels and produce high levels of a pro-angiogenic factor VEGF [28]. Induction of VEGF is highly dependent upon the transcription factor hypoxia inducible factor (HIF)-1 $\alpha$. Studies using cell line models of TSC uncovered mTORC1 as a key mediator of HIF-1 a synthesis, leading to the use of mTORC1 inhibitors in anti-angiogenic therapy. The mTORC1 functions as a master regulator of HIF-1a synthesis, promoting the transcription of HIF-1 $a$ mRNA via STAT3, and its translation via phosphorylation of both $4 \mathrm{E}-\mathrm{BP} 1$ and S6K1. Therefore, activation of HIF- $1 \alpha$ in TSC permits a benign phenotype [29]. Therefore, we checked the expression of CA IX, which is a potent marker of hypoxia [30] to evaluate the hypoxic status in angiomyolipoma samples. Surprisingly, CA9 mRNA was not changed in angiomyolipoma compared to samples from the healthy part of kidney. Also, immunohistochemical staining of AMLs did not reveal presence of CA IX, thus excluding hypoxia in these samples.

In conclusion, our results support the view that $\mathrm{IP}_{3} \mathrm{R} 1$ and $\mathrm{IP}_{3} \mathrm{R} 2$ are involved in angiomyolipoma's ER stress. Nevertheless, further studies are needed to better understand a role of $\mathrm{IP}_{3}$ receptors and calcium signals in these tumors. 
Acknowledgements: Support for this work obtained by VEGA 2/0082/16, APVV-14-0351, APVV-0893-11 and APVV-0045-11 is highly acknowledged.

\section{References}

[1] PALTIEL HJ. Sonography of Pediatric Renal Tumors. Ultrasound Clinics 2007; 2: 89-104. http://dx.doi.org/10.1016/j. cult.2007.01.004

[2] SHEPHERD CW, GOMEZ MR, LIE JT, CROWSON CS. Causes of death in patients with tuberous sclerosis. Mayo Clin Proc 1991; 66: 792-96. http://dx.doi.org/10.1016/S0025-6196(12)61196-3

[3] RANKIN T, ECHEVERRIA A, GREEN DJ, MCCLENATHAN J. Wunderlich syndrome: the role of the general surgeon. Am Surg 2015; 81: E113-4.

[4] ZIMMERHACKL LB, REHM M, KAUFMEHL K, KURLEMANN G, BRANDIS M. Renal involvement in tuberous sclerosis complex: a retrospective survey. Pediatr Nephrol 1994; 8: 451-7. http://dx.doi.org/10.1007/BF00856529

[5] LENDVAY TS, MARSHALL FF. The tuberous sclerosis complex and its highly variable manifestations. J Urol 2003; 169: 1635-42. http://dx.doi.org/10.1097/01. ju. 0000058253.40352 .60

[6] SIROKY BJ, YIN H, BISSLER JJ. Clinical and Molecular Insights into Tuberous Sclerosis Complex Renal Disease. Pediatr Nephrol 2011; 26: 839-852. http://dx.doi.org/10.1007/ $\underline{\text { s00467-010-1689-5 }}$

[7] BISSLER JJ, MCCORMACK FX, YOUNG LR, ELWING JM, CHUCK G et al. Sirolimus for angiomyolipoma in tuberous sclerosis complex or lymphangioleiomyomatosis. N Engl J Med 2008; 358: 140-151. http://dx.doi.org/10.1056/NEJMoa063564

[8] BISSLER J, KINGSWOOD JC, RADZIKOWSKA E, ZONNENBERG BA, FROST $\mathrm{M}$ et al. Everolimus for angiomyolipoma associated with tuberous sclerosis complex or sporadic lymphangioleiomyomatosis (EXIST-2): a multicenter, randomized, double-blind, placebo-controlled trial. Lancet 2013; 381: 817-824. http://dx.doi.org/10.1016/S01406736(12)61767-X

[9] KANG YJ, LU MK, GUAN KL. The TSC1 and TSC2 tumor suppressors are required for proper ER stress response and protect cells from ER stress-induced apoptosis. Cell Death Differ 2011; 18: 133-144. http://dx.doi.org/10.1038/ cdd.2010.82

[10] SIROKY BJ, YIN H, BABCOCK JT, LU L, HELLMANN AR, DIXON BP et al. Human TSC- associated renal angiomyolipoma cells are hypersensitive to ER stress. Am J Physiol - Renal Physiol 2012; 303: F831-F844. http://dx.doi.org/10.1152/ ajprenal.00441.2011

[11] SANO R, REED JC. ER stress-induced cell death mechanisms. Biochim Biophys Acta 2013; 1833: 3460-3470. http://dx.doi. org/10.1016/j.bbamcr.2013.06.028

[12] JOHNSON GG, WHITE MC, GRIMALDI M. Stressed to death: targeting endoplasmic reticulum stress response induced apoptosis in gliomas. Curr Pharm Des 2011; 17: 284-292. http://dx.doi.org/10.2174/138161211795049660
[13] LENCESOVA L, HUDECOVA S, CSADEROVA L, MARKOVA J, SOLTYSOVA A et al. Sulphide signalling potentiates apoptosis through the up-regulation of IP3 receptor types 1 and 2. Acta Physiol (Oxf) 2013; 208: 350-361. http://dx.doi. org/10.1111/apha.12105

[14] LENCESOVA L, VLCEK M, KRIZANOVA O, HUDECOVA S. Hypoxic conditions increases H2S-induced ER stress in A2870 cells. Mol Cell Biochem 2016; 414: 67-76. http://dx.doi. org/10.1007/s11010-016-2659-4

[15] KIVILUOTO S, VERVLIET T, IVANOVA H, DECUYPERE JP, DE SMEDT H, et al. Regulation of Inositol 1,4,5-trisphosphate receptors during endoplasmic reticulum stress. Biochim Biophys Acta 2013; 1833: 1612-24. http://dx.doi. org/10.1016/j.bbamcr.2013.01.026

[16] TAKACOVA M, BARTOSOVA M, SKVARKOVA L, ZATOVICOVA M, VIDLICKOVA I ET AL. Carbonic anhydrase IX is a clinically significant tissue and serum biomarker associated with renal cell carcinoma. Oncol Lett 2013; 5: 191-197.

[17] MEAGLIA JP, SCHMIDT JD. Natural history of an adrenal myelolipoma. J Urol 1992; 147: 1089-1090

[18] HRUZ T, LAULE O, SZABO G, WESSENDORP F, BLEURER S ET AL. Genevestigator V3: a reference expression database for the meta/analysis of transcriptomes. Adv Bioinf 2008; 420747

[19] LENCESOVA L, KRIZANOVA O. IP(3) receptors, stress and apoptosis. Gen Physiol Biophys 2012; 31: 119-130. http:// dx.doi.org/10.4149/gpb 2012014

[20] IVANOVA H, VERVLIET T, MISSIAEN L, PARYS JB, DE SMEDT $\mathrm{H}$ et al. Inositol 1,4,5-trisphosphate receptor-isoform diversity in cell death and survival. Biochim Biophys Acta 2014; 1843: 2164-2183. http://dx.doi.org/10.1016/j. bbamcr.2014.03.007

[21] ADAMS JM, CORY S. The Bcl-2 apoptotic switch in cancer development and therapy. Oncogene 2007; 26: 1324-1337. http://dx.doi.org/10.1038/sj.onc. 1210220

[22] YIP KW and REED JC. Bcl-2 family proteins and cancer. Oncogene 2008; 27: 6398-6406. http://dx.doi.org/10.1038/ onc. 2008.307

[23] CARELLI S, LESMA E, PARATORE S, GRANDE V, ZADRA $\mathrm{G}$ et al. Survivin expression in tuberous sclerosis complex cells. Mol Med 2007; 13: 166-77. http://dx.doi.org/10.2119/200600091.Carelli

[24] ALTIERI A, GALLUS S, FRANCESCHI S, FERNANDEZ E, TALAMINI R et al. Hormone replacement therapy and risk of lymphomas and myelomas. Eur J Cancer Prev 2004; 13: 349-351. http://dx.doi.org/10.1097/01. cej.0000136573.16740.9c

[25] McNEISH IA, LOPES R, BELL SJ, MCKAY TR, FERNANDEZ $M$ et al. Survivin interacts with Smac/DIABLO in ovarian carcinoma cells but is redundant in Smac-mediated apoptosis. Exp Cell Res 2005; 302: 69-82. http://dx.doi.org/10.1016/j. yexcr.2004.08.029

[26] OAKES SA, LIN SS, BASSIK MC. The control of endoplasmic reticulum-initiated apoptosis by the BCL-2 family of proteins. Curr Mol Med 2006; 6: 99-109. http://dx.doi. org/10.2174/156652406775574587

[27] WHITE E. Mechanisms of apoptosis regulation by viral oncogenes in infection and Tumorigenesis. Cell Death 
Differ 2006; 13: 1371-1377. http://dx.doi.org/10.1038/ sj.cdd. 4401941

[28] ARBISER JL, BRAT D, HUNTER S, D‘ARMIENTO J, HENSKE EP et al. Tuberous sclerosis-associated lesions of the kidney, brain, and skin are angiogenic neoplasms. J Am Acad Dermatol 2002; 46: 376-380. http://dx.doi.org/10.1067/ mjd.2002.120530
[29] DODD KM, DUNLOP EA. Tuberous sclerosis-A model for tumour growth. Semin Cell Dev Biol 2016; 52: 3-11. http:// dx.doi.org/10.1016/j.semcdb.2016.01.025

[30] PASTOREK J, PASTOREKOVA S. Hypoxia-induced carbonic anhydrase IX as a target for cancer therapy: from biology to clinical use. Semin Cancer Biol 2015; 31: 52-64. http://dx.doi. org/10.1016/j.semcancer.2014.08.002 